\title{
Microbiological studies on hamburgers
}

\author{
By S. K. TAMMINGA, R. R. BEUMER AND E. H. KAMPELMACHER \\ Laboratory for Food Microbiology and Hygiene, Agricultural University, \\ Wageningen, The Netherlands
}

(Received 29 November 1980)

\begin{abstract}
SUMMARY
One hundred and eighty-two raw, 112 pre-cooked and 750 cooked hamburgers composed mainly of beef or beef and pork were subjected to microbiological examination.

Raw hamburgers gave total bacterial counts from $10^{6}$ to $10^{8}$ per g, counts of Enterobacteriaceae from $10^{4}$ to $10^{6}$ per g, of Escherichia coli from $10^{3}$ to $10^{5}$, of group D streptococci from $10^{2}$ to $10^{4}$, of Staphylococcus aureus from 3 to $10^{2}$ and of Clostridium perfringens less than 10 bacteria per g. Of the samples, $32 \%$ contained salmonellas; the highest most probable number was $10^{2}$ per $\mathrm{g}$ but most estimates were below 1 per g. Corresponding figures for the pre-cooked samples were 2-3 log cycles lower, and only one sample contained salmonella. Yersinia enterocolitica was not isolated from any raw or pre-cooked sample.

Three hundred and ninety-five of the cooked hamburgers were prepared by grilling raw hamburgers for between 2 and $5.5 \mathrm{~min}$. These gave total bacterial counts from $10^{5}$ to $10^{7}$ per $\mathrm{g}$, and counts of Enterobacteriaceae from $10^{2}$ to $10^{5}$ per $\mathrm{g}$. Of the samples, $9 \cdot 4 \%$ contained salmonellas, always in numbers below 1 per $\mathrm{g}$. The remaining 355 cooked hamburgers were prepared from samples pre-cooked for 10 min at $80^{\circ} \mathrm{C}$. Some were grilled and some fat fried. The total bacterial counts were from $10^{3}$ to $10^{5}$ per $\mathrm{g}$, and counts of Enterobacteriaceae below $10^{2}$ per $\mathrm{g}$. Salmonellae, again in small numbers only, were recovered from $3.5 \%$ of samples.

When hamburgers were artificially contaminated with Salmonella typhimurium it took 5.5 min on a commercial grill, 2.25 min frying in a frying pan and $1.75 \mathrm{~min}$ on a household grill to reliably reduce the salmonella count one hundredfold. This means that at many vending places hamburgers are often cooked for too short a time.

D-values were determined for S. typhimurium in hamburger meat at 50, 55, 60, 65 and $70^{\circ} \mathrm{C}$, these values were $7 \cdot 1,5 \cdot 1,1 \cdot 2,0.9$ and $0 \cdot 6$ min respectively. It can be concluded that the heating action in the centre of the hamburgers will take place more slowly than in the hamburger as a whole, and that the time between cooking and consumption is very important in reducing the microbial load to acceptable levels.

Pre-cooking (10 min at $80^{\circ} \mathrm{C}$ in a water bath) gives a reduction in the numbers of salmonella of about $4 \times 10^{3}$, after which cooking gives a further reduction as mentioned above.
\end{abstract}




\section{INTRODUCTION}

Minced meat is a perishable product which can develop unacceptable numbers of micro-organisms in a short time, and which is often contaminated by pathogens. Total bacterial counts of $10^{7}-10^{8}$ per $g$ in the raw product are not exceptional, and coliforms, Escherichia coli, Staphylococcus aureus and Group D streptococci are frequently found (Duitschaever, Arnott \& Bullock, 1973; Surkiewicz et al. 1975; Chambers, Breckbill \& Hill, 1976; Goepfert, 1976, 1977; Pivnick et al. 1976; Westhoff \& Feldstein, 1976; Duitschaever, Bullock \& Arnott, 1977; Foster, Fowler \& Ladiges, 1977; Dempster \& Cody, 1978). In the Netherlands, special attention has been paid to the presence of salmonellas, which have sometimes been found in $30-40 \%$ of raw samples. This contamination is usually heavier when the product contains some pork than when it contains only beef (Van Schothorst, 1971; Edel, Van Leusden \& Kampelmacher, 1978).

The hamburger is a special product consisting of minced meat together with additional ingredients such as soya flour and breaderumbs. Some of the authors cited above have examined hamburgers and found the same levels of contamination as in minced meat in general (Pivnick et al. 1976; Duitschaever, Bullock \& Arnott, 1977; Goepfert, 1977). Some of the studies found salmonellas in up to $4 \%$ of samples. Fontaine et al. (1978) report one outbreak of salmonella food poisoning in the U.S.A. from eating hamburgers raw or insufficiently cooked.

There are fewer reports of investigations of cooked hamburgers ready for immediate consumption. Duitschaever, Bullock \& Arnott (1977) did not detect salmonellas in 107 samples, in which total bacterial counts were usually lower than $10^{4}$ per $\mathrm{g}$, but Mueller (1975) reported salmonellas in 3 of the 13 pre-cooked hamburger samples, and total counts between $10^{4}$ and $10^{5}$ per $\mathrm{g}$. Frying gave a reduction in microbial numbers of about 2 log cycles. This figure agrees with the data of Emswiler et al. (1979) who found reductions of 1.5-2.0 log cycles when cooking beef patties in such a way that an internal temperature of $60-65^{\circ} \mathrm{C}$ was reached.

Increasing consumption of hamburgers in the Netherlands prompted the present studies, which lay special emphasis on the microbial flora of the cooked product and the relationship of cooking method and cooking time to the level of microbial contamination.

\section{MATERIALS AND METHODS}

\section{General materials}

The hamburgers contained minced meat (either beef, or beef and pork) sometimes with the addition of horse meat or soya protein) and generally breadcrumbs as well. The diameter varied between 7 and $10 \mathrm{~cm}$, the thickness was usually about $1 \mathrm{~cm}$, though exceptions up to 4-5 cm occurred.

\section{Commercial raw and pre-cooked hamburgers}

One hundred and eighty-two raw and 112 pre-cooked hamburgers were studied. Pre-cooking is generally done by immersing the hamburgers for about $10 \mathrm{~min}$ in a water bath at about $80^{\circ} \mathrm{C}$, though exceptions to these values may occur; 84 
pre-cooked samples had been prepared this way; 28 samples had been pre-cooked by frying.

Deep frozen samples from large factories were obtained via the Meat Inspection Services. A smaller number of fresh samples were bought in butchers' shops, snack bars and other retail outlets. In a number of cases more than one sample was taken from a batch.

\section{Commercially cooked hamburgers}

Seven hundred and fifty cooked hamburgers ( 5 from each vending point) were bought in snack bars, cafeterias, etc., throughout the country. Upon inquiry, $47 \%$ of the vendors proved to use pre-cooked hamburgers (see above); $21 \%$ of these vendors used fat for frying (155 samples), in the remaining $26 \%$ the hamburgers were grilled ( 200 samples). Of the samples $53 \%$ were prepared from raw hamburgers (395 samples), and these had all been grilled.

The hamburgers were cooked in the presence of the person who bought them. The cooking time was recorded, using a stop watch, without telling the vendor, in order to avoid deviations from the usual procedure. For the same reason the vendor was not informed about the purpose of the purchase.

The vendor was asked not to add onions, in order to avoid the influence of this (raw) ingredient on microbial quality. Ketchup and bun were accepted, because it caused comment to refuse them. As soon as possible after sampling these were separated as completely as possible from the meat. In the following, the word 'hamburger' will be used exclusively for the meat component. All samples were transported without delay to the laboratory in a cool box.

\section{Materials for the laboratory experiments}

Raw hamburgers were bought from a manufacturer, who stated the fat content as about $15 \%$. The hamburgers were, if necessary, stored at $-18^{\circ} \mathrm{C}$.

Temperature measurements were carried out using a Goerz-Servogor potentiometric recorder.

Cooking was done using one of the following:

(a) a grill, as used in restaurants and similar vending places; heating is possible only from one side at a time;

(b) a frying pan, in which the whole hamburger is immersed in hot oil, generally at a temperature of $c a .190^{\circ} \mathrm{C}$;

(c) a household type of grill ('Tefal'), which allows heating from both sides at a time; this grill is, as far as we know, used only in private households.

\section{Microbiological methods of examination}

\section{General}

Decimal dilutions were prepared in peptone physiological saline, PPS (I.S.O. 2293,1976 ), or in a resuscitation medium (vide infra).

The hamburgers were cut in half. One half, including both centre and outer layers, was mixed for 2 min with a ninefold quantity of diluent, using a mixer or stomacher, after which further decimal dilutions were prepared.

All plate counts were done in duplicate, using $1 \mathrm{ml}$ portions for pour plates and 
$0.1 \mathrm{ml}$ for surface counts. When isolated colonies were examined further, a number equal to the square root of the total number of typical colonies were picked, if possible, from plates containing between 30 and 300 colonies. MPN counts were carried out using 3 portions of each quantity ( $1 \mathrm{~g}, 0 \cdot 1 \mathrm{~g}$, etc.)

Total aerobic count

Plate count agar (PCA, I.S.O. 4833, 1978a), was used in pour plates and incubated for 3 days at $30^{\circ} \mathrm{C}$.

\section{Enterobacteriaceae}

For counting, the ISO pour plate method (I.S.O. 5552, 1979) was used, except that the plates were incubated at $30^{\circ} \mathrm{C}$ and the oxidase reaction was done using Pathotec strips.

The counting procedure was preceded by resuscitation for $2 \mathrm{~h}$ at $23^{\circ} \mathrm{C}$ in a thin layer of tryptone soya broth, TSB.

\section{Coliforms}

The ISO pour plate method (I.S.O. 4832, 1978b) was used, but with the covering layer about the same thickness as the base layer. Gas formation in brilliant green bile lactose broth (BGL, I.S.O. 4831, 1978c), was used as a confirmatory test. The counting procedure was preceded by the same resuscitation procedure as that for Enterobacteriaceae.

\section{Escherichia coli}

The same plating method as for coliform was used. Gas formation in BGL broth and indole production from tryptophane, both at $44{ }^{\circ} \mathrm{C}$ (McKenzie, Taylor \& Gilbert, 1948), were used as confirmatory tests.

\section{Group D streptococci}

Surface plates of kanamycin aesculin azide agar (KAAA, Mossel et al. 1976) were incubated for 3-5 days at $37^{\circ} \mathrm{C}$. Specific colonies were confirmed by microscopy, growth at $45^{\circ} \mathrm{C}$ in brain heart infusion broth, $\mathrm{BHI}$, and at $37^{\circ} \mathrm{C}$ in $40 \%$ bile broth.

Salmonella

The ISO-method was followed (I.S.O. 3565, 1975).

Yersinia enterocolitica

Enrichment 1. Of a 1:10 dilution $1 \mathrm{ml}$ was added to 1/15 m phosphate buffer, $\mathrm{pH}=7 \cdot 6$, and incubated for 14-21 days at $4^{\circ} \mathrm{C}$. Isolation was done on lactose sucrose urea agar (Juhlin \& Ericson, 1961) and on desoxycholate citrate lactose agar, DCL, both incubated for 2 days at $29^{\circ} \mathrm{C}$ (Oosterom, 1979).

Enrichment 2. Two drops of a 1:10 dilution were added to Rappaport medium and incubated for 1-2 days at $22^{\circ} \mathrm{C}$. Isolation was done on DCL agar + colimycin, carbenicillin and novobiocin, incubated for $18 \mathrm{~h}$ at $29^{\circ} \mathrm{C}$. Isolates were identified by the methods described by Wauters (1973). 
Staphylococcus aureus

MPN's were estimated using Giolitti-Cantoni broth (GC; Giolitti \& Cantoni, 1966), using $0.3 \mathrm{ml}$ of $0.35 \%$ solution of potassium tellurite per $19 \mathrm{ml}$ of basal medium. The medium was incubated for 1-2 days at $37^{\circ} \mathrm{C}$ and subcultured to Baird-Parker agar (BP, Baird-Parker, 1962). Plate counts were also carried out using BP, on surface plates, incubated as before. Confirmation was by the coagulase reaction read after $6 \mathrm{~h}$.

Clostridium perfringens

MPNs were done in cycloserine broth (CS), the composition of which was as for cycloserine agar (Hauschild \& Hilsheimer, 1974), without agar. Isolation was done on Willis agar (Willis \& Hobbs, 1959), and confirmation using lactose-gelatin medium and nitrate motility medium (Harmon \& Kautter, 1978).

The raw and pre-cooked hamburgers were examined for all the groups of micro-organisms mentioned above. The commercially cooked hamburgers were examined only for total aerobic count, Enterobacteriaceae count and MPN of salmonella, as were the laboratory cooked hamburgers, except for those cooked on the commercial grill, which were also examined for $E$. coli and Group D streptococci.

\section{Preparation and treatment of laboratory cooked samples}

\section{Salmonella suspension}

A strain of S. typhimurium, phage fermentative type II 505, was used. This strain had been isolated from the commercial raw sample with the highest count. It was inoculated into $\mathrm{BHI}$, incubated for $24 \mathrm{~h}$ at $37^{\circ} \mathrm{C}$, and subcultured into a fresh tube of $\mathrm{BHI}$, which was incubated in the same way. The resulting culture was centrifuged, and the cells washed three times using a 1/15 M phosphate buffer, $\mathrm{pH}=7 \cdot 6$. Finally, a suspension of the washed cells was made in this buffer, and stored at $4^{\circ} \mathrm{C}$.

\section{Inoculation of meat}

Hamburger mixture containing $15 \%$ fat was prepared. Beef suet was then added to part of this to raise the fat content to $30 \%$. Generally the fat content of hamburgers is between these limits. The mixtures were inoculated with the salmonella suspension directly or in dilution to give the required levels of contamination. After mincing the mixture was shaped into hamburgers using a plastic Petri dish (diameter $9.5 \mathrm{~cm}$, height $1 \mathrm{~cm}$ ) as a mould.

\section{Determination of the reduction of microbial flora during cooking}

Hamburgers with both 15 and $30 \%$ fat were used in a series of experiments involving each of the three cooking methods mentioned before.

Each of the six expts used 90 hamburgers, inoculated with about $10^{4}$ S. typhimurium per g. Ten were sampled raw. When the commercial grill was used ten were sampled after cooking for $1 \mathrm{~min}(0.5 \mathrm{~min}$ at each side), ten after 2 min ( $1 \mathrm{~min}$ at each side) and so on up to a cooking time of $8 \mathrm{~min}$. For the frying pan and the household grill cooking times were at 0.5 minute intervals to $4 \mathrm{~min}$. 
The temperature of five hamburgers was taken at the end of each cooking process, and also 1 min later.

All samples were examined for salmonella and for the 'natural' flora as described before. Results, including temperatures, were averaged for every cooking time.

After evaluation of the results an additional confirmatory experiment was done for salmonella only; 340 hamburgers were inoculated with about $10^{2}$ salmonellas per $\mathrm{g}$. This was the maximum MPN count obtained in raw commercial samples. Forty of these hamburgers were examined raw. The three cooking methods were each used to cook 100 of the remaining hamburgers. Cooking times were chosen so as to effect an estimated reduction of salmonella of 2 log cycles, which meant $5 \mathrm{~min}$ for the commercial grill (2.5 min on each side), 2 min for the frying pan and 1.5 min for the household grill. All hamburgers thus prepared were examined separately.

\section{Determination of the influence of pre-cooking}

A hundred hamburgers (fat content $15 \%$ ) were inoculated with S. typhimurium (about $10^{4}$ per $\mathrm{g}$ ) and shaped as described before. Five of them were sampled raw. The rest were pre-cooked by immersing in water at $80^{\circ} \mathrm{C}$ for $10 \mathrm{~min}$. The temperature of 18 samples was recorded during pre-cooking and for some time after.

Ten of these pre-cooked hamburgers were sampled without further cooking. The remainder were cooked on the commercial grill, ten being sampled at $1 \mathrm{~min}$ intervals.

Reduction of S. typhimurium numbers in thin layers

Ten grams of hamburger meat, inoculated with $S$. typhimurium (ca. $10^{5}$ per g), was sealed as a thin layer into pouches, made of 'Rilsan' polyamide plastic $(10 \times 5 \mathrm{~cm})$. The initial MPN count of the meat was determined.

Five series of 15 pouches were immersed into water baths, at temperatures of $50,55,60,65$ and $70^{\circ} \mathrm{C}$. The temperature inside the pouches was determined as described before. After 1, 2; 3 and 5 min the salmonella MPN was determined in 3 pouches and the 3 figures averaged. The results were plotted logarithmically, and D-values were calculated, using the least square method.

The experiments were carried out using meat with both 15 and $30 \%$ fat.

\section{RESULTS AND DISCUSSION}

\section{Commercial samples}

\section{General remarks}

Because of the non-homogeneous character of the product, especially as to salmonella content, each sample has been treated individually, even when more than one sample was taken from the same lot. By this treatment we reflect the situation from the point of view of the consumer, who receives only one hamburger at a time.

No differentiation has been made as to thickness, diameter, special ingredients, storage conditions and origin (factories or retail trade), because the results did not warrant this. 


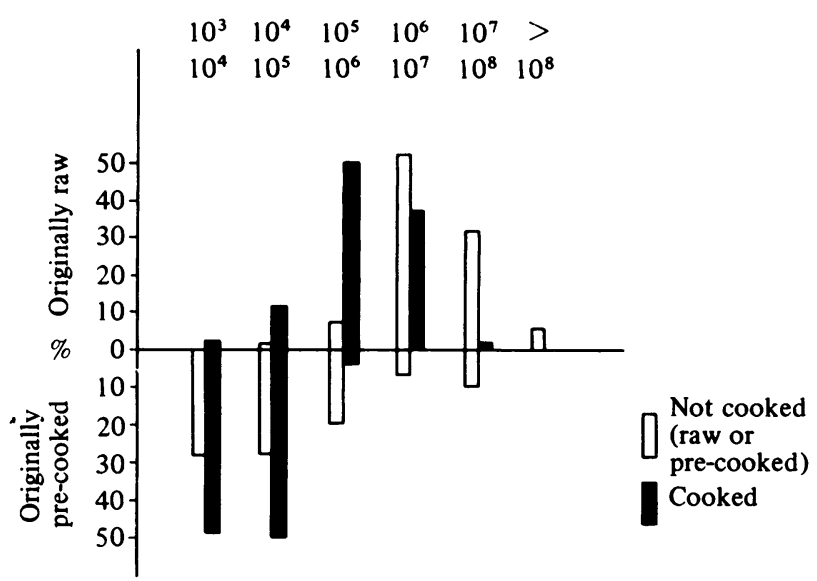

Fig. 1. Total aerobic counts per $g$ in raw, pre-cooked and cooked hamburgers (percentages).

\section{Total aerobic count}

Fig. 1 presents the total aerobic counts for four possible combinations, i.e. cooked or not-cooked, combined with originally raw or originally pre-cooked, grouped in six categories (percentages). The samples pre-cooked by frying (28) are not represented in the graphs, as they came from one manufacturer, though from different lots. They showed total counts of about $10^{5}$ per g.

There is a clear difference between raw and pre-cooked hamburgers, even after cooking. Before cooking the raw samples had counts of $10^{6}-10^{8}$, where most pre-cooked samples had counts 2-3 log cycles lower. Counts of cooked samples were on average about $1 \mathrm{log}$ cycle lower. This would suggest, that pre-cooking reduces microbial numbers more than cooking itself.

Counts for the fat-fried samples were generally somewhat lower than those for the grilled samples (in the figure this distinction has not been made), e.g. $40 \%$ of the grilled, originally pre-cooked samples showed counts below $10^{4}$ per $\mathrm{g}$, the corresponding figure for the fat fried samples was $58 \%$.

\section{Enterobacteriaceae}

Fig. 2 presents the numbers of Enterobacteriaceae, grouped according to the same principles as those for the total counts, but again without the samples pre-cooked by frying, which had counts between 10 and $10^{2}$ per $g$.

When the four combinations mentioned for total counts are compared the figures show the same tendency, albeit on a lower level. As far as the not-cooked samples are concerned, most pre-cooked samples have Enterobacteriaceae counts lower than $10^{4}$ per $\mathrm{g}$, for the raw samples counts are generally higher, i.e. between $10^{4}$ and $10^{6}$ per $\mathrm{g}$. For the cooked samples a corresponding line can be drawn at $10^{2}$ Enterobacteriaceae per gram.

The mean difference between cooked and not-cooked samples is again about one $\log$ cycle. The mean difference between raw and pre-cooked samples is about 3 log cycles. 


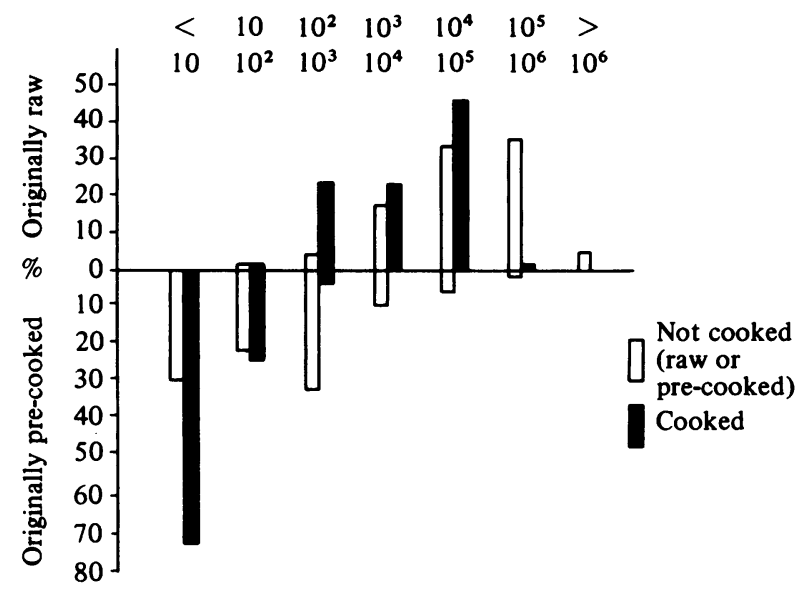

Fig. 2. Enterobacteriaceae counts per $g$ in raw, pre-cooked and cooked hamburgers (percentages).

Table 1. Salmonella most probable numbers for raw, pre-cooked, pre-fried and cooked hamburgers $(M P N / g)$

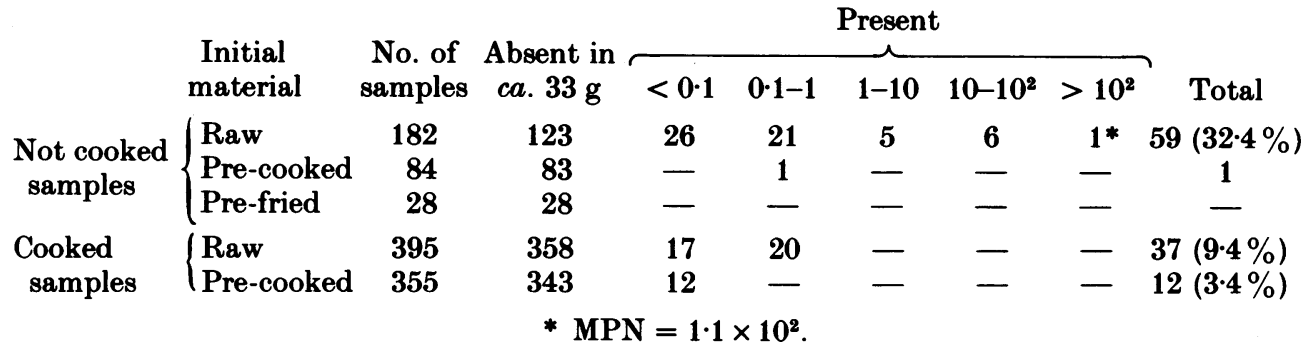

There was hardly any difference between fat-fried and grilled samples.

From additional experiments, carried out with the raw samples, it was concluded that the majority of the Enterobacteriaceae-isolates belonged to the coliform group. In $70 \%$ of the samples coliform counts were equal to or only slightly lower than those for Enterobacteriaceae. On an average, $E$. coli counts amounted to about $10 \%$ of those for Enterobacteriaceae.

No Enterobacteriaceae were isolated from buns or ketchup.

\section{Salmonella}

In Table 1 figures are given for the MPN of salmonella. They were detected in more than $30 \%$ of the raw samples, in numbers sometimes up to about $10^{2}$ per $\mathrm{g}$. Pre-cooking, cooking, even both, apparently do not result in the complete disappearance of these bacteria, though percentages and MPN's are lower.

Though there is a broad correlation between presence of salmonella and Enterobacteriaceae counts (see Table 2), aberrations are frequent.

About $50 \%$ of the strains found in raw samples and about $25 \%$ of those from 
Table 2. Correlation between Enterobacteriaceae and presence of salmonella in hamburgers*

Raw

Enterobacteriaceae

$$
45 \quad 40 \%
$$

$10^{4}-10^{5}$

$6022 \%$

$10^{5}-10^{6}$

$6840 \%$

$9 \begin{array}{r}>10^{6} \\ 78 \%\end{array}$

E. coli

$$
\begin{array}{ll}
<7 \quad 10^{3} \\
21 \%
\end{array}
$$

$10^{3}-10^{4}$

$6632 \%$

$10^{4}-10^{5}$

$60 \quad 37 \%$

$9 \begin{aligned} & >10^{5} \\ & 78 \%\end{aligned}$

Cooked, originally raw

Enterobacteriaceae

$$
107 \begin{array}{r}
<0^{3} \\
5 \%
\end{array}
$$

$$
\begin{aligned}
& 10^{3}-10^{4} \\
& 96 \quad 5 \%
\end{aligned}
$$

$10^{4}-10^{5}$
182
$11 \%$

$10 \begin{gathered}>10^{5} \\ 70 \%\end{gathered}$

Cooked, originally

pre-cooked

Enterobacteriaceae

$$
261<10
$$

$$
10-10^{2}
$$

$866 \%$

$$
\begin{array}{ll}
> & 10^{2} \\
8 & 25 \%
\end{array}
$$

* Within each category the left hand figure indicates the total number of samples in that category; the right hand figure indicates the percentage of that number in which salmonellas were detected.

Numbers of Enterobacteriaceae and $E$. coli are per gram.

cooked samples belonged to S. typhimurium, phage-fermentative type II 505, which in the Netherlands is also the type isolated in the majority of human cases of salmonellosis. Other phage-fermentative types of $S$. typhimurium, and S. panama were frequently found.

\section{Other groups of micro-organisms in raw and pre-cooked samples}

Counts for Group D streptococci were generally between $10^{2}$ and $10^{4}$ per $\mathrm{g}$ for the raw samples. Occasionally numbers up to $10^{5}$ were found. Counts in the pre-cooked samples were mostly below $10^{2}$ per $\mathrm{g}$, though numbers up to $10^{4}$ per $\mathrm{g}$ were also detected.

In the majority of the raw samples small numbers of S. aureus were found, mostly below $10^{3}$ per $\mathrm{g}$, and in $50 \%$ of the samples below $10^{2}$ per $\mathrm{g}$. The pre-cooked samples mostly contained numbers below $10^{2}$ per $\mathrm{g}$. Occasionally numbers up to $8 \times 10^{3}$ per $\mathrm{g}$ were detected in both types.

MPN counts for Clostridium perfringens were below 3 per g in $52 \%$ of the raw samples; $8 \%$ contained more than 10 per g. Of the pre-cooked samples $87 \%$ had MPNs below 3 per $\mathrm{g}$, no sample showed counts higher than 10 per $\mathrm{g}$.

$Y$. enterocolitica could not be detected when $0 \cdot 1 \mathrm{~g}$ was examined.

\section{The effect of cooking time}

For the cooked samples there is a clear correlation between starting material (raw or pre-cooked) and method of cooking (fat-frying or grilling) on the one hand, and cooking time on the other hand (see Fig. 3A). Shorter times are applied for fat-frying than for grilling (average $c a .2 v .3 \mathrm{~min}$ ). As already mentioned the microbial qualities of fat-fried and grilled samples nevertheless are almost equal, obviously due to a better heat penetration in the former case. Raw samples are grilled for a longer time than those already pre-cooked (average ca. 3.5 v. $3 \mathrm{~min}$ ).

For the grilled, originally raw, samples there is a correlation between cooking 


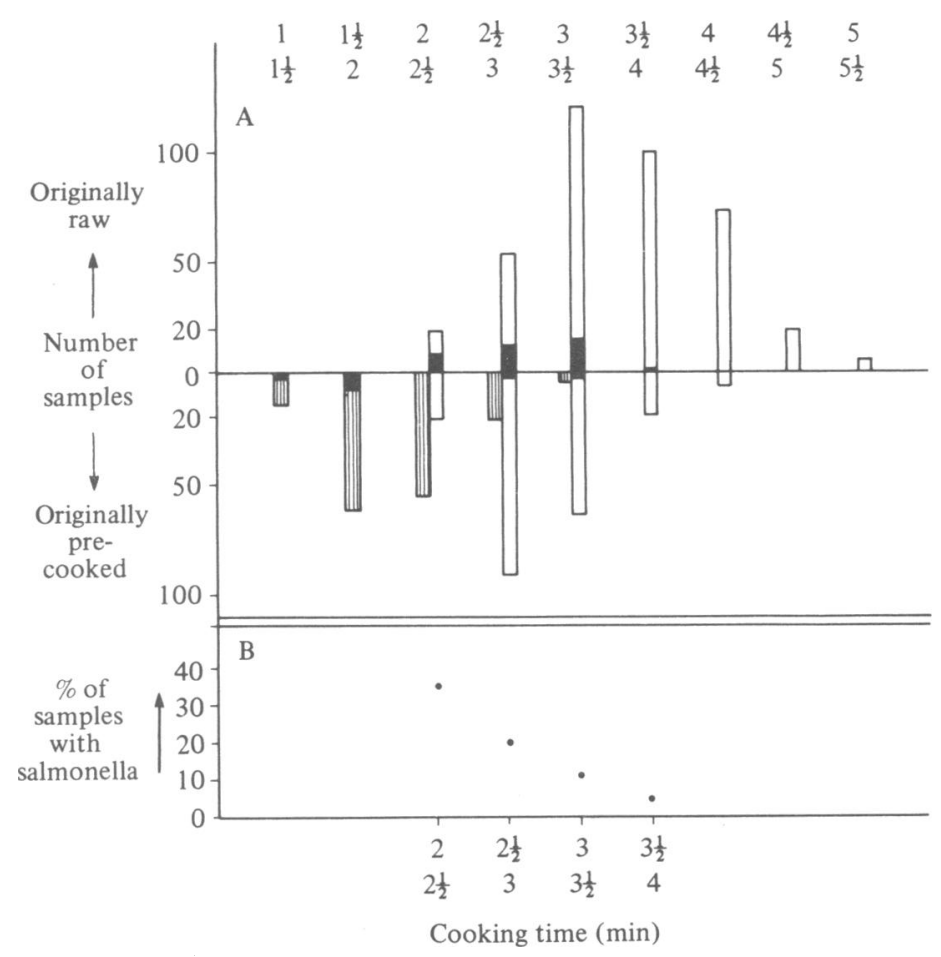

Fig. 3. A. Number of samples in three groups of hamburgers in relation to cooking times. ( $\square$, grilled; 四, fat-fried; $\square$, number with salmonella). B. Percentage of grilled, originally raw samples in each category of cooking times.

time and percentage of samples containing salmonella (Fig. 3 B). Similar correlations are also observed for Enterobacteriaceae (Table 3).

It should be noted that, when samples with short cooking times were investigated, the inside of many of them looked rather raw.

\section{Heating experiments in the laboratory}

Reduction in microbial numbers for different cooking methods

Fig. 4 shows the MPNs of salmonella in relation to cooking times, for the three different methods. Graphs are also given for the temperatures in the centre of the hamburgers, directly after cooking and 1 min later.

Lines are given only for hamburgers with $15 \%$ fat. Heat penetration in those containing $30 \%$ fat was somewhat faster, resulting in lower MPN's, but, as the maximal difference was about $3^{\circ} \mathrm{C}$ and 0.2 log cycles, lines representing these figures have been omitted for the sake of clarity.

Graphs for some other microbial parameters have been given in Fig. 5.

There is a considerable difference in the rate of heat penetration and reduction of the numbers of salmonella between the three methods, especially between commercial grilling and the other two methods. 
Table 3. Relationship between cooking time and Enterobacteriaceae counts

Initial material and method of preparation

Raw, grilled

Pre-cooked, fat fried

Pre-cooked, grilled
Enterobacteriaceae counts per gram

$$
\begin{array}{r}
<10^{3} \\
10^{3}-10^{4} \\
>10^{4}
\end{array}
$$$$
<10
$$$$
>10
$$$$
<10
$$$$
>10
$$

Cooking time $(\min )^{*}$

\begin{tabular}{lrrr}
\hline 2 & $2-3$ & $3-4$ & $>4$ \\
- & - & 35 & 74 \\
- & 5 & 64 & 22 \\
- & 70 & 121 & 4 \\
43 & 70 & 5 & - \\
32 & 5 & - & - \\
- & 77 & 61 & 5 \\
- & 33 & 25 & -
\end{tabular}

* Number of samples in each category.

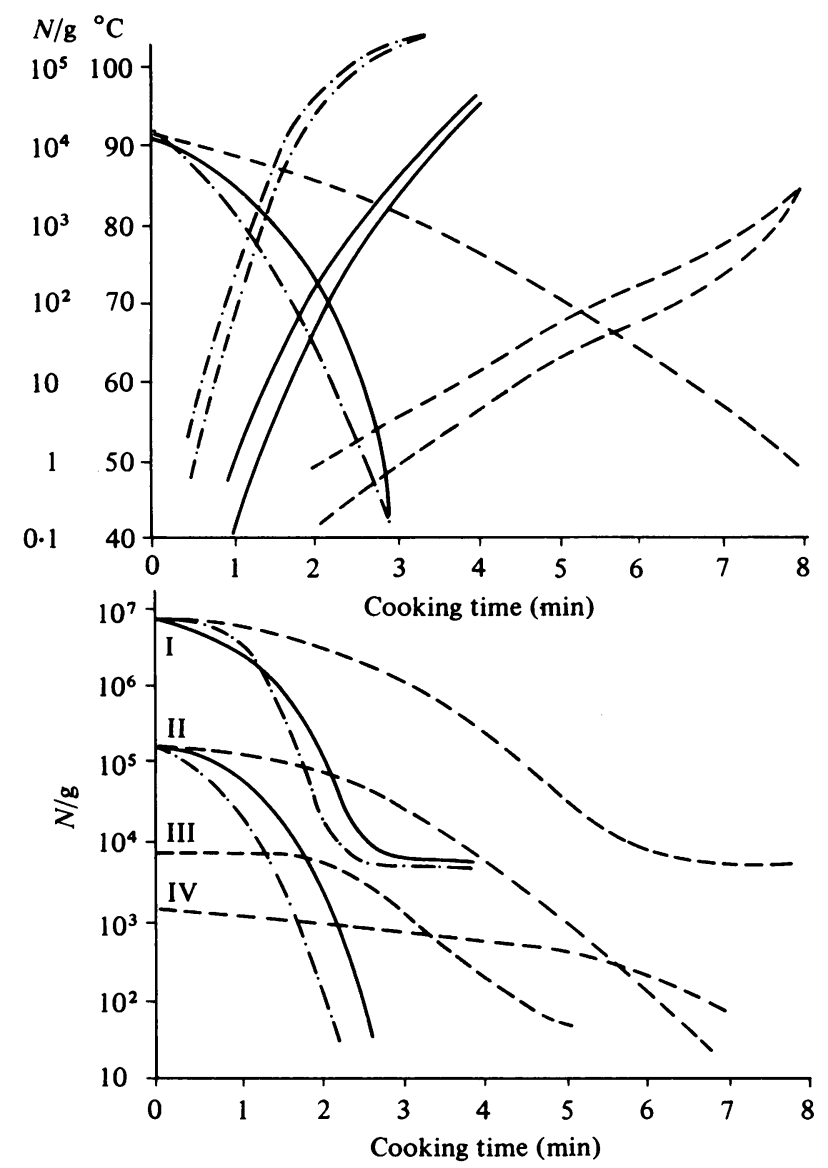

Fig. 4. MPNs of salmonella in hamburgers (15\% fat) (descending lines), and temperatures in the centre of the hamburgers immediately after frying and 1 min later (rising lines), all in relation to cooking times, for the three cooking methods. N/g $=$ MPN per $g$; ${ }^{\circ} \mathrm{C}=$ temperature $\left({ }^{\circ} \mathrm{C}\right) .---$, commercial grill; - , frying pan; ---, household grill.

Fig. 5. Total aerobic count (I), and counts of Enterobacteriaceae (II), E. coli (III) and D-streptococci (IV) in hamburgers (15\% fat) in relation to cooking times, I and II for the three cooking methods, III and IV for commercial grill only. $\mathrm{N} / \mathrm{g}$, numbers per $\mathrm{g}$. -. -, commercial grill; - , frying pan; - -- , household grill. 
Table 4. MPNs of salmonella after cooking 100 hamburgers for the times indicated, when the initial number was $1 \cdot 1 \times 10^{2}$ (figure determined as an average of 40 hamburgers; range $7.5 \times 10-2.1 \times 10^{2}$ )

\begin{tabular}{|c|c|c|c|c|c|}
\hline Method & $\begin{array}{l}\text { Cooking } \\
\text { time (min) }\end{array}$ & $\begin{array}{c}\text { MPN/g } \\
\text { (average) }\end{array}$ & Range* & $\begin{array}{l}\text { Number with } \\
\text { MPN } 1 \cdot 1-2 \cdot 4\end{array}$ & $\begin{array}{l}\text { MPN/g, read } \\
\text { from Fig. } 4 \dagger\end{array}$ \\
\hline Commercial grill & 5 & 0.71 & $0 \cdot 20-2 \cdot 4$ & 35 & $0 \cdot 87$ \\
\hline Frying pan & 2 & $0 \cdot 82$ & $0 \cdot 15-2 \cdot 4$ & 31 & 1.5 \\
\hline Household grill & 1.5 & $0 \cdot 78$ & $0 \cdot 15-2 \cdot 4$ & 39 & $1 \cdot 7$ \\
\hline
\end{tabular}

* Lowest and highest values in the 100 hamburgers.

$\dagger$ Numbers, read from Fig. 4 (i.e. if the reduction rate had been the same as that in Fig. 4) at the same cooking time and provided the initial number had been $1.1 \times 10^{2}$.

The temperature rise continues after the cooking process has been finished.

As calculated from the graphs, a reduction in numbers of salmonella by a factor of $10^{2}$ takes $4.8 \mathrm{~min}$ using the commercial grill, $2 \cdot 2 \mathrm{~min}$ when frying is done in fat, and $1.6 \mathrm{~min}$ using the household grill. The temperatures in the centre will rise during this time to 62,69 and $87^{\circ} \mathrm{C}$ respectively, and $1 \mathrm{~min}$ later the temperature will be 67,73 and $90^{\circ} \mathrm{C}$. A reduction by a factor $10^{3}$ takes $6 \cdot 4,2 \cdot 6$ and $2 \cdot 1 \mathrm{~min}$ respectively. The corresponding final temperatures are 70,75 and $95{ }^{\circ} \mathrm{C}$, and 74 , 78 and $97^{\circ} \mathrm{C}$, respectively after $1 \mathrm{~min}$.

Reduction of the 'natural' Enterobacteriaceae flora proceeds in the same way as for salmonella (Fig. 5). Determination of the total aerobic count results in a line becoming gradually almost horizontal, probably due to the presence of sporeforming and other thermoresistant bacteria. The reduction in numbers is about $3 \log$ cycles. The line for streptococci is very flat when compared, for instance, with that for $E$. coli, indicating the thermoresistance of the former group.

\section{Additional cooking experiment}

Results with a greater number of hamburgers and an inoculation of salmonella in agreement with the maximum number found in commercial raw samples (i.e. $c a .10^{2}$ per $\mathrm{g}$ ), using cooking times supposed to give a reduction factor of about $10^{2}$, are summarized in table 4. Final average numbers tend to be somewhat lower than those obtained if the reduction rate had been the same as that for the experiments described in the previous section. Many individual samples, however, retain relatively high salmonella counts. In view of these samples an increase in cooking time corresponding to $\log 2 \cdot 4 / 1 \cdot 1=0.34$ would be needed to reach a $2 \log$ cycles reduction for all samples, which means (reading from Fig. 4), for the commercial grill about $0.5 \mathrm{~min}$ and for frying pan and household grill about $0.25 \mathrm{~min}$, i.e. total cooking times of $5 \cdot 5,2.25$ and 1.75 min respectively.

Reduction of S. typhimurium numbers in thin layers

The counts of salmonella in the meat in the plastic pouches produced logarithmic curves, except for the initial counts, as the internal pouch temperature took 50-60 s to reach that of the water-bath. D-values were calculated using the figures after 1, 2, 3, 4 and 5 min (see Table 5).

The values are rather high when compared with figures in the literature obtained under optimal conditions. Factors such as water activity and the presence of fat, 
Table 5. D-values of S. typhimurium II 505 in hamburger meat with 15 and $30 \%$ of fat

\begin{tabular}{ccc} 
& \multicolumn{2}{c}{ D-values (min) } \\
\cline { 2 - 3 } Temperature $\left({ }^{\circ} \mathrm{C}\right)$ & $\overbrace{15 \% \text { fat }}$ & $30 \%$ fat \\
50 & $7 \cdot 1$ & $6 \cdot 0$ \\
55 & $5 \cdot 1$ & $4 \cdot 9$ \\
60 & $1 \cdot 2$ & $1 \cdot 2$ \\
65 & 0.9 & $1 \cdot 0$ \\
70 & $0 \cdot 6$ & $0 \cdot 6$
\end{tabular}

Table 6. Logarithmic reduction of S. typhimurium II 505 in hamburgers, overall effect and effect in centre

\begin{tabular}{|c|c|c|c|c|c|}
\hline \multirow[b]{2}{*}{ Method } & \multirow{2}{*}{$\begin{array}{l}\text { Time } \\
(\min )\end{array}$} & \multirow{2}{*}{$\begin{array}{l}\text { Overall } \\
\text { effect* }\end{array}$} & \multicolumn{3}{|c|}{ Effect in centre } \\
\hline & & & Total & Cooking & After $1 \mathrm{~min}$ \\
\hline Commercial grill & $\begin{array}{l}4 \\
4 \cdot 5 \\
5 \\
5 \cdot 5\end{array}$ & $\begin{array}{l}1 \cdot 50 \\
1 \cdot 80 \\
2 \cdot 10 \\
2 \cdot 50\end{array}$ & $\begin{array}{l}0 \cdot 70 \\
1 \cdot 20 \\
1 \cdot 85 \\
2 \cdot 55\end{array}$ & $\begin{array}{l}0 \cdot 20 \\
0 \cdot 35 \\
0 \cdot 75 \\
1 \cdot 20\end{array}$ & $\begin{array}{l}0.50 \\
0.85 \\
1 \cdot 10 \\
1.35\end{array}$ \\
\hline Frying pan & $\begin{array}{l}1 \cdot 5 \\
1 \cdot 75 \\
2 \\
2 \cdot 25\end{array}$ & $\begin{array}{l}1 \cdot 10 \\
1 \cdot 40 \\
1 \cdot 85 \\
2 \cdot 20\end{array}$ & $\begin{array}{l}0.40 \\
1 \cdot 00 \\
1 \cdot 75 \\
\text { Not } t\end{array}$ & $\begin{array}{r}\sim 0 \\
0 \cdot 10 \\
0 \cdot 35 \\
\text { alculate }\end{array}$ & $\begin{array}{c}0.40 \\
0.90 \\
1 \cdot 40 \\
-\end{array}$ \\
\hline Household grill & $\begin{array}{l}1.5 \\
1.75\end{array}$ & $\begin{array}{l}1 \cdot 80 \\
2 \cdot 25\end{array}$ & $\begin{array}{l}\text { Not to } \\
\text { Not } t\end{array}$ & $\begin{array}{l}\text { alculate } \\
\text { alculate }\end{array}$ & - \\
\hline
\end{tabular}

* Read from Fig. 4.

† Calculated using D-values (Table 5); the total effect, the effect as a consequence of the cooking itself and the effect as a consequence of 1 min keeping after cooking, in the order given.

reported in literature to have a protective effect on micro-organisms, may play a role in this (Baird-Parker, Boothroyd \& Jones, 1970; Goepfert, Iskander \& Amundson, 1970; Gibson, 1973; Corry, 1974).

\section{Distinction between central and peripheral effect}

Because of the shape of hamburgers it is difficult to make a distinction between the microbial conditions in the centre and at the periphery by direct examination. However, when applying the results given in the previous section to the temperature and MPN graphs given in Fig. 4, the relative influence of the reduction rate in the centre on the overall reduction in numbers can be estimated. The lower temperature graphs, between $50{ }^{\circ} \mathrm{C}$ and the temperature corresponding to the desired cooking time, were divided into steps of $0 \cdot 1-0 \cdot 2 \mathrm{~min}$. For each of these short periods the average temperature was read from the graphs, and the corresponding $D$-value was, if necessary, calculated by interpolation. Temperature and D-value were considered constant during each of these short periods. For every step the lethal effect was calculated. The same procedure was carried out for a period of 1 min after cooking. These effects were summed up. Below $50^{\circ} \mathrm{C}$ the effect, for the short times applied, was considered negligible. At temperatures higher than $70^{\circ} \mathrm{C}$ calculation 
was not possible because no $\mathrm{D}$-values were available. For this reason, no figures can be given for the hamburgers cooked on the household grill. The results are given in Table 6. For comparison figures for the total effect read from the graphs in Fig. 4 are also given.

For short cooking times, the total or a major part of the lethal effect in the centre is caused during the minute after cooking. In the centre reduction lags behind when compared with the total effect, appreciable reduction takes place only in the outer layers. When cooking time is short, heat penetration obviously should be considered almost negligible.

For longer cooking times the calculated effect in the centre approaches more and more the total effect as read from the graphs. Even then, however, the $1 \mathrm{~min}$ keeping period remains important. In view of the preparation after cooking in restaurants, etc. (addition of a bun, ketchup, etc.), and the fact that there will be some delay after receiving before the consumer starts eating, it can be assumed that, also under practical conditions, a short time will elapse between cooking and consumption.

\section{The effect of pre-cooking}

With an initial temperature of $6.5^{\circ} \mathrm{C}, 10 \mathrm{~min}$ pre-cooking in a water bath at $80^{\circ} \mathrm{C}$ resulted in a temperature in the centre of $71.0^{\circ} \mathrm{C}$ (average of 18 samples). If the hamburgers were subsequently cooled in running cold water, the average centre temperatures after 1,2 and $4 \mathrm{~min}$ were $72 \cdot 1,70 \cdot 9$ and $49 \cdot 2^{\circ} \mathrm{C}$ respectively.

The average salmonella MPNs were reduced by pre-cooking from $1.1 \times 10^{4}$ to 2.8 per $\mathrm{g}$. When the pre-cooked samples were grilled on the commercial grill salmonella was detectable in the samples fried for up to $5 \mathrm{~min}$. After $6 \mathrm{~min}$ they were absent.

The total aerobic count was reduced by pre-cooking from $1.2 \times 10^{6}$ to $2.1 \times 10^{4}$ per $\mathrm{g}$. When the samples were then grilled the count was reduced to $1.4 \times 10^{3}$ per $\mathrm{g}$ after $8 \mathrm{~min}$. During this time the same flattening of the reduction line took place as shown in Fig. 4 for cooking initially raw samples. The total reduction of microbial numbers for pre-cooking and grilling together was about 3 log cycles, which is about the same as that for cooking only, in the laboratory experiments using initially raw material.

\section{CONCLUSIONS}

These experiments show, in agreement with other authors, that raw minced meat is contaminated by a wide range of micro-organisms, often present in large numbers. The level of micro-organisms, especially that of hygienic indicator organisms, draws attention, yet again, to measures which might be taken to counteract the consequences of the unavoidable original contamination of meat during slaughtering, such as cooling, limitation of storage period and regular cleaning and disinfection of apparatus and utensils. The value of the indicator organisms in judging the possibility of the presence of pathogenic organisms is very limited, for example when Enterobacteriaceae counts are relatively low, a considerable percentage of samples may still contain salmonella (Table 2) (cf. Miskimin et al. 1976; Newton, 1979). 
The fact, that in Dutch hamburgers salmonella is found relatively often is probably caused by the habit in this country of using a beef and pork mixture in many cases, as pork is more often contaminated by these bacteria than beef (cf. Introduction).

A striking feature of the data obtained for commercial samples (Figs 1 and 2 and Table 1) was the relatively small difference between raw and cooked samples. Moreover, a considerable number of salmonella-positive cooked samples were present. Though raw and cooked samples had different origins and so no quantitative conclusions from these figures could be drawn, this was an indication that something was wrong. The short cooking times were considered important in this respect, as there was a broad correlation between cooking times and microbial quality. Additional proof was the almost raw state of the centre in many of the samples with short cooking times.

From Fig. 3 it was observed that the first group of commercially cooked hamburgers in which salmonella was not detected (i.e. numbers lower than 0.03 per $\mathrm{g}$ ) were those with cooking times between 4 and $4.5 \mathrm{~min}$ for grilled samples and between 2 and $2.5 \mathrm{~min}$ for fat-fried samples. It would appear that, to incorporate something of a safety margin, the minimal cooking time should be no longer than that corresponding to the lower limit, e.g. $4.5 \mathrm{~min}$ for grilled samples and $2.25 \mathrm{~min}$ for fat-fried samples.

When the results of the laboratory cooking experiments are considered, for the fat-fried samples the cooking time mentioned means an average reduction of well over $2 \log$ cycles (Table 6), in all probability also in the centre. In the case of samples grilled on the commercial grill, however, some doubts may arise, when the calculated figures for the reduction in the centre are taken into consideration. An estimated lethal effect of $\mathbf{1 . 2 0}$ is hardly more than one log cycle. If samples are grilled for 5.5 min an average reduction of well over 2 log cycles is obtained both for the overall effect and for the estimated effect in the centre. These figures are in agreement with those deduced from the 'additional cooking experiment' (see Results and Discussion section).

For the household grill, by its very nature, no commercial figures are available, but, using the figures from Table 6 and from the 'additional cooking experiment', a cooking time of 1.75 min would appear sufficient.

It is interesting to note that, when the average cooking time for commercially grilled, originally raw hamburgers $(3.5 \mathrm{~min})$ is applied to Fig. 5 for the hamburgers prepared correspondingly in the laboratory, the reduction factors read from the graphs (for Enterobacteriaceae and total count) are only slightly more than one log cycle. This is a difference about as small as that previously mentioned between commercial raw and cooked samples. Though in the latter case raw and cooked samples were from different origins, results of the laboratory experiments indicate that no better quality of cooked commercial samples could have been expected!

It should be borne in mind that, even with the above mentioned recommendations, in the case of originally raw initial material, no absolute guarantee can be given. In the laboratory experiments Enterobacteriaceae counts, after the above cooking times, were still well over $10^{2}$ per $\mathrm{g}$. When a large proportion of this group is of a pathogenic nature (not only salmonella but, for instance, yersinia) or when the initial load in the raw product is heavier (cf. Fig. 2) some of the pathogenic bacteria 
might still survive. In fact, the detection of high salmonella counts in some of the raw samples (Table 1) is an indication of this possibility.

Likewise, it will be obvious from this study that it is unwise to eat hamburger meat in its raw state, even in small quantities.

The microbial quality can still be improved by pre-cooking of the raw hamburger before frying or grilling, which is of course not meant to say that in this way every lot of half spoilt minced meat can be made fit for preparing hamburgers. The reduction rate for Enterobacteriaceae and salmonella during pre-cooking in the laboratory experiments was between 3 and 4 log cycles, so that with an original bacterial load of, say, $10^{8}$ per $\mathrm{g}$ many of them would still survive, this apart from the aesthetic and organoleptic objections.

$C l$. perfringens were present only in small numbers and even less so when some pretreatment had been applied. They seem to be present mainly in the vegetative state, which is in agreement with the well-known low sporulation characteristics of this species.

For $S$. aureus higher counts were sometimes found, even in the pre-cooked samples. However, in the majority of samples counts were below the detection limit of 3 per $g$.

From the figures gathered, the risk of food poisoning by these species seems low. Raw and pre-cooked hamburgers are generally stored deep-frozen or at refrigerator temperatures. Even in the latter case no growth will take place. For $S$. aureus especially the competing flora (Enterobacteriaceae) seems an additional inhibitory factor (DiGiacinto \& Frazer, 1966; McCoy \& Faber, 1966). The only risk would arise if hamburgers are stored after cooking at temperatures favourable for the development of these two species, possibly helped by a post-cooking contamination. Since most hamburgers are cooked only when they have been ordered, this risk seems small.

We gratefully acknowledge the co-operation of the following persons and/or institutions: Dr P.A.M. Guinée, National Salmonella Centre, National Institute of Public Health, RIV, Bilthoven, for typing the salmonella strains. Dr J. Oosterom, RIV, for advice about the examination for yersinia. Meat Inspection Departments at Amsterdam, Arnhem, Deventer, Helmond, Rotterdam, Tilburg and Utrecht for collecting the frozen samples. Encko BV, Holten, for making available large quantities of hamburger meat necessary for the laboratory experiments, and help in preparing it for these experiments. Mr T. van der Laan (Agricultural University) for technical assistance.

\section{REFERENCES}

BaIrd-Parker, A. C. (1962). An improved diagnostic and selective medium for isolating coagulese positive staphylococci. Journal of Applied Bacteriology 25, 12-19.

Baird-Parker, A. C., Boothroy D, M. \& Jones, E. (1970). The effect of water activity on the heat resistance of heat sensitive and heat resistant strains of Salmonella. Journal of Applied Bacteriology 33, 515-522.

Chambers, J. V., Breckbill, D. O. \& Hill, D. A. (1976). A microbiological survey of ground beef in Ohio. Journal of Milk and Food Technology 39, 530-535.

Corry, J. E. L. (1974). The effect of sugars and polyols on the heat resistance of salmonella. Journal of Applied Bacteriology 37, 31-43. 
Dempster, J. F. \& Cody, O. H. (1978). Bacteriological and chemical status of minced beef. Irish Journal of Food Technology 2, 1-11.

Digiacinto, J. V. \& Frazer, W. C. (1966). Effect of coliform and Proteus bacteria on growth of Staphylococcus aureus. Applied Microbiology 14, 124-129.

Duitschaever, C. L., Arnott, D. R. \& Bullock, D. H. (1973). Bacteriological quality of raw, refrigerated ground beef. Journal of Milk and Food Technology 36, 375-377.

Duitschaever, C. L., Bullock, D. H. \& ARnott, D. R. (1977). Bacteriological evaluation of retail ground beef, frozen beef patties and cooked hamburger. Journal of Food Protection 40, 378-381.

Edel, W., Leusden, F. M. van \& Kampelmacher, E. H. (1978). Salmonella in gehakt afkomstig van 10 vleeskeuringsdiensten in Nederland. Tijdschrift voor Diergeneeskunde 103, 220-228.

Emswiler, B. S., Pierson, C. J., Kotula, A. W. \& Cross, H. R. (1979). Microbiological evaluation of pre-cooked beef patties containing soya protein. Journal of Food Science 44, 154-157.

Fontaine, R. E., Arnon, S., Martin, W. T., Vernon Jr, T. M., Gangarosa, E. J., Farmer III, J. J., Moran, A. B., Silliker, J. H. \& DeCker, D. L. (1978). Raw hamburger: An interstate common source of human salmonellosis. American Journal of Epidemiology 107, 36-45.

Foster, J. F., Fowler, J. L. \& Ladiges, W. C. (1977). A bacteriological survey of raw ground beef. Journal of Food Protection 40, 790-794.

Gibson, B. (1973). The effect of high sugar concentration on the heat resistance of vegetative micro-organisms. Journal of Applied Bacteriology 36, 365-376.

Giolitti, G. \& Cantoni, C. (1966). A medium for the isolation of staphylococci from foodstuffs. Journal of Applied Bacteriology 29, 395-398.

GOEPFERT, J. M. (1976). The aerobic plate count, coliform and Escherichia coli content of raw ground beef at the retail level. Journal of Milk and Food Technology 39, 175-178.

GOEPFERT, J. M. (1977). Aerobic plate count and Escherichia coli determination on frozen ground-beef patties. Applied and Environmental Microbiology 34, 458-460.

Goepfert, J. M., Iskander, I. K. \& Amundson, C. H. (1970). Relation of the heat-resistance of salmonellae to the water activity of the environment. Applied Microbiology 19, 429433.

HaRmon, S. M. \& KaUtTer, D. A. (1978). Media for confirming Clostridium perfringens from food and feces. Journal of Food Protection 41, 626-630.

Hauschild, A. H. \& Hilsheimer, R. (1974). Evaluation and modifications of media for enumeration of Clostridium perfringens. Applied Microbiology 27, 78-82.

I.S.O. 3565 (1975). International Standard ISO 3565. Meat and Meat Products-Detection of Salmonella (Reference Method), 1st ed. 1975-09-01. Geneva: International Organization for Standardization.

I.S.O. 2293 (1976). International Standard ISO 2293. Meat and Meat Products-Aerobic count at $30 \mathrm{C}$ (Reference Method), 1st ed. Geneva: International Organization for Standardization.

I.S.O. $4833(1978 a)$. International Standard ISO 4833. Microbiology-General Guidance for Enumeration of Micro-organisms - Colony Count Technique at 30 C, 1st ed. 1978-02-01, Geneva: International Organization for Standardization.

I.S.O. $4832(1978 b)$. International Standard ISO 4832. Microbiology-General Guidance for Enumeration of Coliforms - Colony Count Technique at 30 C, 1st ed. 1978-02-01. Geneva: International Organization for Standardization.

I.S.O. 4831 (1978c). International Standard ISO 4831. Microbiology-General Guidance for the Enumeration of Coliforms-Most probable Number Technique at $30 \mathrm{C}$, 1st ed. 1978-08-15. Geneva: International Organization for Standardization.

I.S.O. 5552 (1979). International Standard ISO 5552. Meat and Meat Products - Detection and Enumeration of Enterobacteriaceae (Reference Methods), 1st ed. 1979-04-01. Geneva: International Organization for Standardization.

Juhlin, I. \& ERICSON, C. (1961). A new medium for the bacteriologic examination of stools (LSU-agar). Acta Pathologica et Microbiologica Scandinavica 52, 185-200.

McCoy, D. W. \& FABER, J. E. (1966). Influence of food micro-organisms on staphylococcal growth and enterotoxin production in meat. Applied Microbiology 14, 372-377.

McKenzie, E. F. W., TAYlOR, E. W. \& Gilbert, W. E. (1948). Recent experiences in the rapid identification of Bacterium coli type I. Journal of General Mirsobiology 2, 197-204. 
Miskimin, D. K., Berkowitz, K. A., Solberg, M., Riha Jr. W. E.. Franke. W. C.. Bichasax. R. L. \& O'LeARY, V. (1976). Relationship between indicator organism and specific pathogen in potentially hazardous foods. Journal of Food science 41, 1(0)1-1(0)6.

Mossel, D. A. A., Eelderink, I., Vor, H. de \& K eizer, E. I). (1976). L'se of agar immersion. plating and contact (AIPC) slides for the bacteriological monitoring of food. meals and the food environment. Laboratory Practice 25, 393-395.

Mueller, D. C. (1975). Microbiological safety and palatability of selected vended burgers. Journal of Milk and Food Technology 38, 135-137.

Newton, K. G. (1979). Value of coliform tests for assessing meat quality. Journal of Applied Bacteriology 47, 303-307.

Oosterom, J. (1979). Isolation and epidemiological significance of Versinia enterorolitica. Antonie van Leeuwenhoek, Journal of Microbiology 45, 630-633.

Pivnick, H., Erdman, I. E., Collins-Thompson, D., Roberts. ( D. R., Lachapelle, G., Punvis, U. T., Foster. R. \& Mililing. M. (1976). Proposed microbiological standards for ground beef based on a ('anadian survey. Journal of Milk and Food Technology 39, 408-412.

Schothorst, M. van (1971). Hygiënische aspecten van de vleeswarenbereiding. l'oedingsmiddelentechnologie 2(4), 6-8.

Surkiewicz, B. F., Harkis, M. E., Elllott, R. P., Macaluso, J. F.. Ntrani), M. M. (197it). Bacteriological survey of raw beef patties produced at est ablishments under federal inspection. Applied Microbiology 29, 331-334.

Wauters, G. (1973). Contributions to Microbiology and Immunology, vol. - (ed. A. (arümbach). pp. 68-70. Basel: Karger.

Westhoff, D. \& Feldostein, F. (1976). Bacteriological analy sis of ground beef. Jourmal of .Milk. and Food Technology 39, 401-404.

Willis, A. T. \& HobBs, (7. (1959). Some new media for the isolation and identitication of Clostridia. Journal of Pathology and Bacteriology 77, 511. 